\title{
PALB2: research reaching to clinical outcomes for women with breast cancer
}

Melissa C. Southey ${ }^{1 *}$, Ingrid Winship ${ }^{2,3}$ and Tú Nguyen-Dumont ${ }^{1}$

\begin{abstract}
PALB2 has taken its place with bona fide breast cancer susceptibility genes. It is now well established that women who carry loss-of-function mutations in the PALB2 gene are at similarly elevated breast cancer risks to those who carry mutations in BRCA2. Information about PALB2 is now being used in breast cancer clinical genetics practice and is routinely included in breast cancer predisposition gene panel tests. Tens of thousands of women worldwide have now had genetic tests for PALB2 mutations in the context of breast cancer susceptibility. However, prospective data related to the clinical outcomes of PALB2 mutation carriers is lacking and very little information (beyond mutation penetrance) is available to guide current clinical management for carriers (affected and unaffected by cancer). In addition, clinical classification of the vast array of non-loss-of-function genetic variants identified in PALB2 is in its infancy. These are key areas of current research efforts and are important foundations on which to move information about PALB2 into the precision public health arena.
\end{abstract}

Keywords: PALB2, Breast cancer susceptibility, Cancer susceptibility, Familial cancer

\section{Introduction}

For the last two decades, women have been offered genetic testing of $B R C A 1$ and $B R C A 2$ in various clinical contexts. The vast majority of these women are seeking an explanation for a personal or family history of breast and/or ovarian cancer, and an accurate means of risk assessment, to facilitate risk management across the family. Indeed clinical criteria used to determine eligibility for $B R C A 1$ and $B R C A 2$ testing in many settings have been founded on the number of affected relatives and their age at diagnosis and then developed over time with increased evidence and local practice issues. Of those women who undergo testing, up to $20 \%$ are found to carry a clinically actionable mutation in $B R C A 1$ or $B R C A 2$. Until very recently additional genetic testing was not possible unless other clinical indicators were present (such as Li-Fraumeni syndrome that might indicate genetic testing of TP53). Women and their families who received uninformative genetic test results for $B R C A 1$ and $B R C A 2$ were clinically managed solely on the basis of their personal and family history. This limited the use of invasive strategies such as risk reduction surgery.

\footnotetext{
* Correspondence: msouthey@unimelb.edu.au

'Genetic Epidemiology Laboratory, Department of Pathology, The University of Melbourne, Parkville, VIC 3010, Australia

Full list of author information is available at the end of the article
}

Continued research and a recent revolution in genetic technology that can be applied to this research has identified a number of additional breast cancer predisposition genes and reported a large number of additional candidate breast cancer predisposition genes that are yet to be validated. This same technology has also transitioned into molecular diagnostic laboratories and has enabled a shift from high cost single gene genetic tests to lower cost multi-gene panel tests. The uptake of gene panel tests has been rapid and included a volume of successful direct-tothe-public marketing. In some areas of clinical genetics, panel testing is now the standard of care [1]. With some important caveats and considerations discussed in this review, current data suggests that gene panel testing offers breast cancer clinical genetics practice increased opportunity to identify "actionable" genetic variants in a greater proportion of women [2-4].

However, few of the large number of genes included in many gene panel tests are bona fide breast cancer predisposition genes and the vast majority of genetic variation identified by these gene panel tests cannot be interpreted in terms of breast or ovarian cancer risk. This is currently a controversial area of breast cancer research and clinical genetics practice, and is discussed in detail elsewhere [5]. 
PALB2 has now firmly taken its place with the small number of bona fide breast cancer susceptibility genes. It is now well established that women who carry mutations in the PALB2 gene are at similar breast cancer risks as those who carry mutations in $B R C A 2[6,7])$ making many rethink the appropriateness of the initial "moderate or intermediate risk gene" label [8]. PALB2 now plays a legitimate role in breast cancer clinical genetics practice and takes a valid place on breast cancer predisposition gene panel tests. Internationally, tens of thousands of women, including those who have gone direct to the test provider, have had genetic tests for PALB2 mutations in the context of breast cancer susceptibility. Today, many nations have (or are preparing) best practice guidelines that include recommendations for PALB2 genetic testing and risk management $[5,9]$.

Currently, prospective data related to the clinical outcomes of PALB2 mutation carriers is lacking and very little information (beyond mutation penetrance) is available to guide clinical management for carriers (affected and unaffected by breast cancer). Over the last two decades, evidence has slowly been accumulated to support recommendations around risk management and targeted treatment regimes for $B R C A 1$ and $B R C A 2$ mutation carriers. Very little of this evidence currently exists for PALB2 mutation carriers.

Accumulating this evidence is challenging due to the very low frequency of women with PALB2 mutations, even in affected women with a strong family history of breast and ovarian cancer. However, with new technology and international coordination there is promise that further evidence could be gathered for PALB2 mutation carriers that will improve their clinical care within a few years.

In addition, risk estimates for PALB2 mutations have been based on collections of loss-of-function mutations. Clinical classification of the vast array of non-loss-offunction genetic variants identified in PALB2 is in its infancy. Informed by prior research in this area involving unclassified genetic variants in $B R C A 1$ and $B R C A 2$, international initiatives are moving quickly to identify the best approaches to assess PALB2 genetic variants on a variantby-variant basis, to enable personalized use in clinical genetics practice.

PALB2 has made it over the first hurdle and is now included in the breast cancer clinical genetics arena but to extend current utility and have an impact on improving the clinical outcomes for carriers of PALB2 mutations and incorporate use of this genetic information into precision public health initiatives, additional data is still urgently required.

\section{PALB2: A bona fide breast cancer susceptibility gene} Mutations in PALB2 make a small contribution to heritable breast cancer susceptibility in most populations.
Germline PALB2 mutations and carrier frequencies have been reviewed elsewhere [10]. Briefly, protein truncating mutations in PALB2 are distributed throughout the coding region $[6,10]$ yet four $P A L B 2$ mutations are of note in terms of multiple observations: PALB2 c.509_510delGA (p.Arg170fs*14) in Poland [11], PALB2 c.2323C > T (p.Gln775*) in French Canadians [12], PALB2 c.1592delT (p.531 fs*30) in Finland [13] and PALB2 c.3113G > A identified in affected women in the UK, USA and Australia [8, 14-17]. Reports from a variety of populations consistently estimate that PALB2 mutations are associated with increased risk for breast cancer (e.g., OR 3.94, 95 \% CI, 1.5-12.1) [13].

As few studies have been conducted within unselected breast cancer cases, estimation of the age-specific cumulative risk (penetrance) of breast cancer associated with PALB2 mutations has been limited. The family histories of the case carriers, unselected for age or family history, reported in Northern Finland [13], were used to estimate PALB2 c.1592delT to be associated with a $40 \%$ (95\% CI, $17 \%-77 \%)$ risk of breast cancer to the age of 70 years [18]. Similarly, an Australian population-based case-control-family study of breast cancer estimated the cumulative risk for PALB2 c.3113G > A to be $91 \%$ (95\% CI, 44-100\%) to the age of 70 years [17].

To consider penetrance of a larger number of PALB2 genetic variants and a larger number of families, the PALB2 interest group [19] embarked on a collaborative effort that collected data from 362 members of 154 families who had deleterious truncating, splice, or deletion mutations in PALB2 [6]. The estimated average cumulative risk of breast cancer risk ranged from $33 \%(95 \%$ CI, 25-44 \%) for a female carrier without affected relatives to $58 \%$ (95\% CI, 50-66 \%) for a female carrier with two first-degree relatives who had breast cancer diagnosed by 50 years of age. Supported by other similar observations [20], some recommend that both family history and PALB2 genotype should be considered together for clinical breast cancer risk management.

Thus, all published estimates of penetrance of PALB2 mutations are comparable to the breast cancer risk associated with BRCA2 mutations: $45 \%$ (95 \% CI, 31-56 \%) [7]. PALB2 is now regarded as a bona fide breast cancer predisposition gene and is justifiably included on current breast cancer gene testing panels with the above evidence.

\section{Evidence-based translation into breast cancer clinical genetics practice}

An overview of the pathway to translation of new genetic information related to breast cancer clinical genetics practice is shown in Fig. 1. This figure represents women diagnosed with breast cancer under the age of 40 years with a strong family history of breast and or ovarian cancer (two or more effected first or second degree 


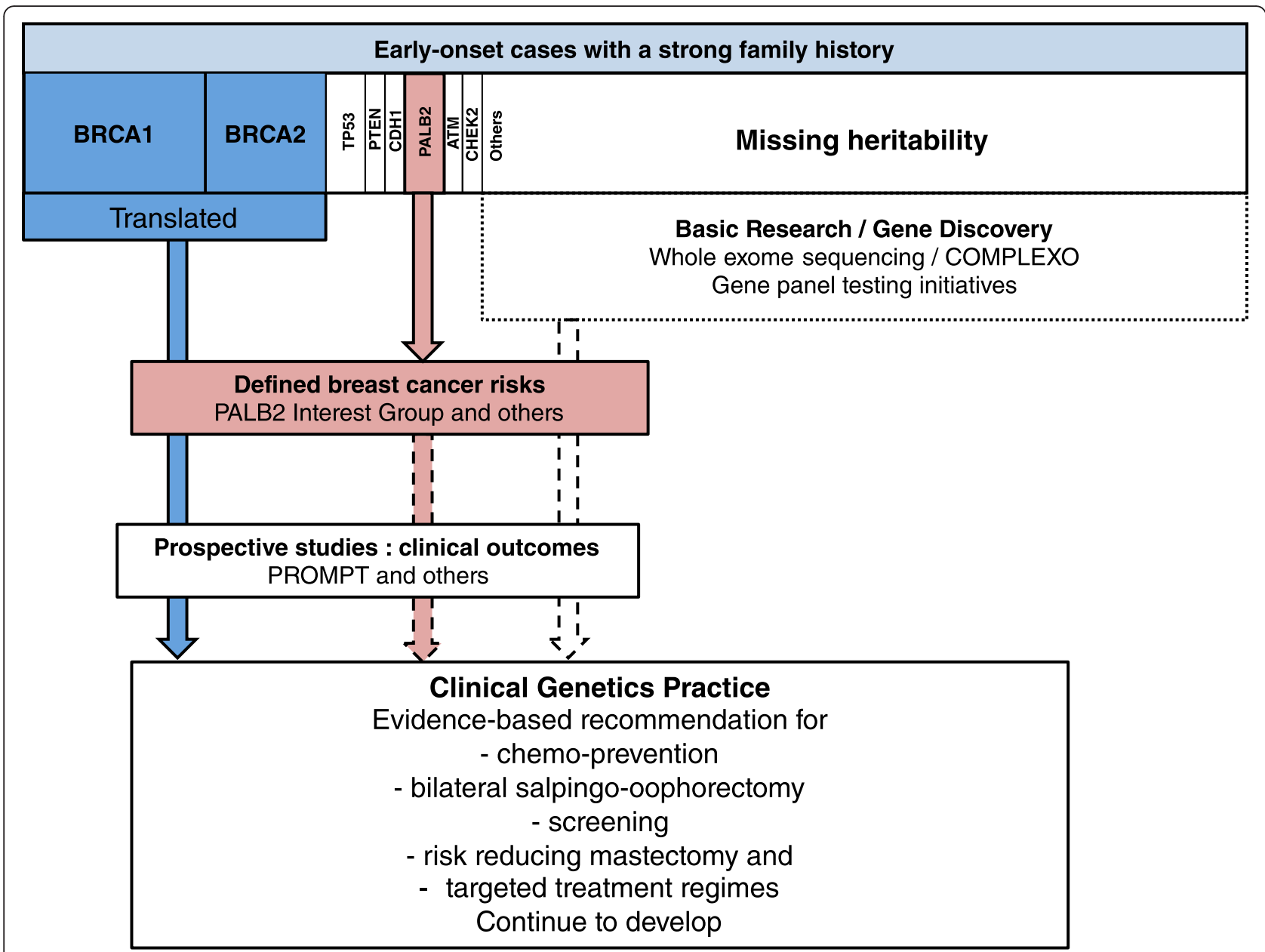

Fig. 1 PALB2: evidence-based translation into practice. Based on the Australian Breast Cancer Family Registry and the Australian context

relatives). Pathogenic mutations in BRCA1 and BRCA2 have been identified in approximately $25 \%$ of these women. The risk associated with carrying these mutations and the clinical outcomes for these women (collectively) have been well characterised and this evidence is used to inform the clinical management of these women and their families [21]. Loss-of-function PALB2 mutations are identified in approximately $2 \%$ of these women [17]. Breast cancer risk associated with carrying a PALB2 loss-offunction mutations is now established but research is urgently needed to extend this knowledge to an understanding of clinical outcomes for carriers. Rare mutations in genes associated with genetic syndromes such as Li-Fraumeni (TP53), Cowden syndrome (PTEN) and hereditary diffuse gastric cancer $(C D H 1)$ are also present in this group of women at very low frequency. Specific evidence related to clinical outcomes for breast cancer in these contexts is lacking. Additional breast cancer susceptibility genes including $A T M$ and $C H E K 2$ also require prospective data to provide the evidence-base for clinical decision making around risk management/reduction and treatment options. Several other genes have been identified as candidate breast cancer predisposition genes that require further validation such as FANCM [22] and RECQL [23]. The remaining early-onset breast cancer cases with a strong family history remain the subject of research trying to identify the "missing heritability" of breast cancer via numerous initiatives including COMPLEXO [24].

\section{PALB2 mutations and risk of other cancer types}

As PALB2 functions together with BRCA1 and BRCA2, in the same DNA-damage response pathway, it has been thought plausible that $P A L B 2$ mutations, similar to $B R C A 1$ and $B R C A 2$ mutations, could predispose to other cancer types. The rarity of mutations in PALB2 and the rarity of some of the other cancers likely to be involved (pancreatic, male breast cancer, ovarian cancer, prostate cancer) make the estimation of the risk (if any) extremely challenging. Data in this area continues to come from small (yet important) studies and case reports that accumulatively may assist this interpretation ([25] and many others). By pooling international resources, the PALB2 Interest Group 
estimated that the relative risk of ovarian cancer and male breast cancer for PALB2 mutation carriers was 2.31 (95 \% CI, 0.77-6.97; $P=0.18)$ and 8.30 (95\% CI, $0.77-88.56 ; P=0.08)$ respectively [6].

$P A L B 2$ germline mutations are rare in cases of pancreatic cancer [26-32]. A recent report describing the mutational landscape of pancreatic cancers has illustrated the potentially important role for paralleling somatic and germline mutation testing to enable the identification not just of the rare germline PALB2 mutation carriers but also the mutation signature of DNA damage repair deficiency in pancreatic cancers that could benefit from platinum therapies [33].

Some substantial opportunities to assess risk for other cancers have come from application of targeted sequencing projects and gene panel testing. In the context of risk for ovarian cancer, Ramus et al. have reported sequencing results for PALB2 for 3,236 women affected with epithelial ovarian cancer and 3,431 unaffected women. Nine mutation carriers were identified in the affected women and three in the unaffected women $(P=0.08)$. Interestingly they also identified seven carriers in 2,000 unaffected women with a family history of breast or ovarian cancer (all women had at least $10 \%$ lifetime risk) ( $P=0.045$ when compared to the controls above) [34]. Norquist et al. have reported findings from a targeted capture and massively parallel sequencing assay that included the identification of 12 PALB2 mutation carriers in a group of 1,915 women with ovarian cancer unselected for family history $(P=<0.001$ when compared to data from the Exome Sequencing Project and the Exome Aggregation Consortium) [35]. Two protein truncating mutations in PALB2 (c.1592delT, p.Leu531Cysfs and c.3113G > A, p.Trp1038*) were included on the iCOGS and genotyped in 16,287 ovarian cancer cases and 23,491 controls. No evidence for association with ovarian cancer risk was observed (OR 2.50, $95 \% \mathrm{CI}, 0.21-29.1$ ), $p=0.45$ and OR 1.34, $95 \% \mathrm{CI}, 0.36-4.97), p=0.66$ respectively) (Southey MC, Goldgar D, Winqvist R, Pylkas K, Couch FJ, Tischkowitz M.: PALB2, CHEK2 and ATM rare variants and cancer risk: data from COGS, unpublished).

There is still very little data and no evidence supporting an association between PALB2 mutations and prostate cancer risk [13, 36-39] although several pedigrees have been presented and a possible trend toward aggressive disease in carriers has been noted [39]. iCOGS measured PALB2 (c.1592delT, p.Leu531Cysfs and c.3113G > A, p.Trp1038*) in 22,301 prostate cancer cases and 22,320 controls and found no evidence for association with prostate cancer risk OR 2.06, $95 \%$ CI $0.59-7.11, p=0.24$ and OR $0.49,95 \%$ CI, $0.18-$ $1.36, p=0.16$ respectively.

The PALB2 interest group continues work to further refine breast and other cancer risks for PALB2 mutation carriers [19].

\section{PALB2 mutation carriers: clinical outcomes}

As described above, recent work has increased the precision of breast cancer risk estimates for PALB2 mutation carriers providing some new information with clinical utility. However, prospective data related to the clinical outcomes of PALB2 mutation carriers is lacking and very little information (beyond mutation penetrance) is available to guide current clinical management for carriers (affected and unaffected by breast cancer).

It has taken decades of research to provide the evidence base for BRCA1 and BRCA2 mutation carriers to make informed decision about the use of chemo-preventive agents, the use of the bilateral salpingo-oophorectomy, the use of mammography, magnetic resonance imaging (MRI) and other screening modalities, risk reducing mastectomy and targeted treatment regimes. Accumulating this evidence was challenging due in part to the very low frequency of women with $B R C A 1$ and BRCA2 mutations, the historically laborious and expensive process of testing for mutations in these genes and the need to follow these women prospectively.

However, in today's context where PALB2 is being included in gene panel tests that are being conducted rapidly in large numbers at reduced costs and research can be conducted in a coordinated fashion internationally involving well established research resources (including resources founded to assess these questions for $B R C A 1$ and BRCA2 mutation carriers) and in community-academicindustry partnerships - there is promise that evidence can be found for PALB2 mutation carriers that will impact clinical practice in the short term.

In the only report of its kind so far, Cybulski et al, identified 116 carriers of either 509_510delGA or 172_175delTTGT in 12,529 women diagnosed with invasive breast cancer in Poland. Ten-year survival for women with breast cancer and a PALB2 mutation was $48.0 \%$ (95 \% CI, $36.5 \%-63.2 \%$ ), compared with $74.7 \%$ (95\% CI, $73.5 \%-75.8 \%)$ for non-carriers (hazard ratio for death 2.27, $95 \% \mathrm{CI}, 1.64-3.15 ; p<0.0001$ ) [40]. Some other data indirectly supports a likely worse outcome for PALB2 mutation carriers, including the propensity in some population for PALB2 mutation-associated breast cancers to be of higher grade, including triple negative. However, these reports are few and small in size, are variable in findings and suggest PALB2 mutation-specific tumour phenotypes [14, 15, 20, 41].

Further studies are required to test if women who carry PALB2 mutations are at increased risk of death from breast cancer compared to non-carriers. More information is needed to understand the options for prevention and risk reduction. Intuitively, given the similar biological role of the protein, it is likely that some of the recommendations for $B R C A 1$ and $B R C A 2$ mutation carriers, including therapeutic regimes, may be relevant for 
PALB2 mutation carriers - but much work is needed to resolve these questions.

To this end, a new academic-industry partnership named PROMPT - Prospective Registry of Multiplex Testing $[42,43]$, and many other large research initiatives are underway to address these important questions for carriers. PROMPT has scope beyond addressing these questions for $P A L B 2$ alone and will support the rapid translation of similar information for several new breast cancer predisposition genes including $A T M, C D H 1$, CHEK2, RAD51C, RAD51D, STK11, TP53 in addition to $B R C A 1$ and BRCA2. PROMPT is an online research registry for people who have undergone gene panel testing and been found to have a genetic variation in one of the above genes. PROMPT is one of several initiatives that create a new paradigm for research study participation that directly involves the most relevant community. PROMPT is designed to involve those who want to share their genetic results, learn more from sharing these results and engage at a level of their choosing/comfort as a collaborator alongside physicians and researchers to learn more about how mutations in these genes (such as PALB2) may affect their health and cancer risks.

\section{Classification of rare variants}

In contrast to several other breast cancer predisposition genes, there is no evidence that missense variants in PALB2 (as a combined group) are associated with increased risk for breast cancer [44, 45]. We and others have reported that the breast cancer risk fraction contributed by missense variants in BRCA1, BRCA2, ATM and CHEK2 is as high, if not higher, than proteintruncating variants in these genes [46-48]. However, interpretation of the rare genetic variation observed in PALB2 on a variant-by-variant basis, especially the rare missense variants, remains challenging [44]. That is, on a variant-by-variant basis it is difficult provide any information that can be used to guide clinical management of carriers of rare missense mutations.

In some practices, the previous approach of breast cancer clinical genetics to generalize risk within groups of similar mutations (e.g., protein truncating mutations in $B R C A 1$ ) has not been automatically applied in the context of $P A L B 2$ due to i) a perception that the PALB2 risk estimates currently include data from a disproportionate number of the founder PALB2 mutations (and thus may not represent the average risk associated with all loss-of-function mutations) and ii) the more recent characterisation of variants in BRCA1 (e.g., R1699Q $[49,50]$ ) and BRCA2 (e.g., K3326* [51, 52]) with more moderate or low risk of breast cancer that is also a plausible scenario for variants in other genes, including PALB2.
There is therefore a need to extend international efforts that are currently trying to classify rare variants identified in BRCA1 and BRCA2 for clinical use to include rare variants identified in PALB2 (and other genes) to assist the clinical management of the individuals who carry them. Several activities are well underway.

The most extensive and internationally set groups working in this area include The PALB2 Interest Group $[6,19]$ and The Evidence-based Network for the Interpretation of Germline Mutation Alleles (ENIGMA) [53-55] whose members are providing a range of data to accumulate new evidence on a variant-by-variant basis to be assessed in multifactorial risk models. These groups are also providing expert opinion to global databases and classification initiatives and working to communicate new information to clinical genetics practices urgently in need of individualized information.

The assessment and clinical classification of rare missense variants in PALB2 are likely to require incorporation of many pieces of evidence to enable clinical utility. Some of this evidence is likely to come from so-called functional assays. Fortunately, several functional domains of PALB2 are recognized including a coiled-coil structure, an ETGEtype KEAP1 binding motif, a chromatin-association motif (ChAM) at the N-terminus and a WD repeat motif in the C-terminus (reviewed elsewhere [10]). These domains, coupled with PALB2's role in DNA repair and Fanconi anemia, are facilitating work that is pitched at assessing the functional differences between wildtype PALB2 and PALB2 carrying rare missense mutations in key functional domains. Park et al., characterized effects of missense mutations of the PALB2 WD40 domain and demonstrated that PALB2 L939W (c.2816 T > G) and PALB2 L1143P (c.3428 T > A) display a decreased capacity for DNA double-strand break-induced homologous recombination and an increased cellular sensitivity to ionizing radiation [56]. This data offers much potentially useful information for rare variant classification - yet key questions still need to be answered. For instance, 1) how should these assays be calibrated (i.e., how much change of function equates to increased cancer risk)?; 2) is the magnitude of functional change proportional to magnitude of cancer risk?; 3) how should these results be coded, weighted and incorporated into multifactorial risk models?

Calibrated assays for functional assessment of variants in $B R C A 1$ and $B R C A 2$ have been developed and reported $[57,58]$. Recently, a publically available resource for functional analysis of missense variants in BRCA1 (BRCA1 Circos) has been made available to facilitate meta-analysis of functional data and improve classification of variants in that gene [59]. It is anticipated that groups such as the Functional Working Group of ENIGMA [60] will be able to develop similar resources for PALB2 once assays are further developed and data is available. 


\section{Conclusions: towards precision medicine}

There is much well founded optimism in the research community that a number of large initiates (some detailed here) will generate data quickly, on the necessary scale and pooled to make definitive analyses related to variant classification and clinical outcomes for $P A L B 2$ carriers a reality in the near future.

\section{Competing interests}

The authors declare that they have no competing interests.

\section{Authors' contributions}

All authors contributed to the writing of this manuscript and approved the final version.

\section{Acknowledgements}

MCS is a Senior Research Fellow of the National Health and Medical Research Council of Australia.

\section{Author details}

${ }^{1}$ Genetic Epidemiology Laboratory, Department of Pathology, The University of Melbourne, Parkville, VIC 3010, Australia. ${ }^{2}$ Department of Medicine, The University of Melbourne, Parkville, VIC 3010, Australia. ${ }^{3}$ The Royal Melbourne Hospital, Parkville, VIC 3050, Australia.

\section{Received: 7 February 2016 Accepted: 11 April 2016}

Published online: 19 April 2016

\section{References}

1. Zentner D, Thompson TN, James PA, Trainer A, Ades LC, Macciocca I, et al. The cardiac genetics clinic: a model for multidisciplinary genomic medicine. Med J Aust. 2015;203(6):261:e1-6.

2. Kurian AW, Hare EE, Mills MA, Kingham KE, McPherson L, Whittemore AS, et al. Clinical evaluation of a multiple-gene sequencing panel for hereditary cancer risk assessment. J Clin Oncol. 2014:32(19):2001-9. doi:10.1200/JCO. 2013.53.6607.

3. Desmond A, Kurian AW, Gabree M, Mills MA, Anderson MJ, Kobayashi Y, et al. Clinical actionability of multigene panel testing for hereditary breast and ovarian cancer risk assessment. JAMA Oncol. 2015;1(7):943-51. doi:10. 1001/jamaoncol.2015.2690.

4. Thompson ER, Rowley SM, Li N, Mclnerny S, Devereux L, Wong-Brown MW et al. Panel Testing for Familial Breast Cancer: Calibrating the Tension Between Research and Clinical Care. J Clin Oncol. 2016. doi:10.1200/JCO.2015.63.7454.

5. Easton DF, Pharoah PD, Antoniou AC, Tischkowitz M, Tavtigian SV, Nathanson $\mathrm{KL}$, et al. Gene-panel sequencing and the prediction of breast-cancer risk. N Engl J Med. 2015:372(23):2243-57. doi:10.1056/NEJMsr1501341.

6. Antoniou AC, Casadei S, Heikkinen T, Barrowdale D, Pylkas K, Roberts J, et al. Breast-cancer risk in families with mutations in PALB2. N Engl J Med. 2014; 371(6):497-506. doi:10.1056/NEJMoa1400382.

7. Antoniou A, Pharoah PDP, Narod S, Risch HA, Eyfjord JE, Hopper JL, et al. Average risks of breast and ovarian cancer associated with BRCA1 or BRCA2 mutations detected in case Series unselected for family history: a combined analysis of 22 studies. Am J Hum Genet. 2003:72(5):1117-30.

8. Rahman N, Seal S, Thompson D, Kelly P, Renwick A, Elliott A, et al. PALB2, which encodes a BRCA2-interacting protein, is a breast cancer susceptibility gene. Nat Genet. 2007:39(2):165-7.

9. EviQ Cancer Treatment Online. https://www.eviq.org.au.

10. Southey MC, Teo ZL, Winship I. PALB2 and breast cancer: ready for clinical translation! Appl Clin Genet. 2013:6:43-52. doi:10.2147/TACG.S34116.

11. Dansonka-Mieszkowska A, Kluska A, Moes J, Dabrowska M, Nowakowska D, Niwinska A, et al. A novel germline PALB2 deletion in Polish breast and ovarian cancer patients. BMC Med Genet. 2010;11:20. doi:10.1186/1471-2350-11-20.

12. Foulkes WD, Ghadirian P, Akbari MR, Hamel N, Giroux S, Sabbaghian N, et al Identification of a novel truncating PALB2 mutation and analysis of its contribution to early-onset breast cancer in French-Canadian women. Breast Cancer Res. 2007:9(6):R83. doi:10.1186/bcr1828.

13. Erkko H, Xia B, Nikkila J, Schleutker J, Syrjakoski K, Mannermaa A, et al. A recurrent mutation in PALB2 in Finnish cancer families. Nature. 2007:446(7133): 316-9. doi:10.1038/nature05609.
14. Casadei S, Norquist BM, Walsh T, Stray S, Mandell JB, Lee MK, et al. Contribution of inherited mutations in the BRCA2-interacting protein PALB2 to familial breast cancer. Cancer Res. 2011;71(6):2222-9. doi:10. 1158/0008-5472.CAN-10-3958.

15. Teo ZL, Sawyer SD, James PA, Mitchell G, Trainer AH, Lindeman GJ, et al. The incidence of PALB2 C.3113G > A in women with a strong family history of breast and ovarian cancer attending familial cancer centres in Australia. Fam Cancer. 2013;12(4):587-95. doi:10.1007/s10689-013-9620-4.

16. Teo ZL, Park DJ, Provenzano E, Chatfield CA, Odefrey FA, Nguyen-Dumont T, et al. Prevalence of PALB2 mutations in Australasian multiple-case breast cancer families. Breast Cancer Res. 2013:15(1):R17. doi:10.1186/bcr3392.

17. Southey MC, Teo ZL, Dowty JG, Odefrey FA, Park DJ, Tischkowitz M, et al. A PALB2 mutation associated with high risk of breast cancer. Breast Cancer Res. 2010;12(6):R109. doi:10.1186/bcr2796.

18. Erkko H, Dowty JG, Nikkila J, Syrjakoski K, Mannermaa A, Pylkas K, et al. Penetrance analysis of the PALB2 C.1592delT founder mutation. Clin Cancer Res. 2008:14(14):4667-71. doi:10.1158/1078-0432.CCR-08-0210.

19. PALB2 Interest Group. http://www.palb2.org

20. Heikkinen T, Karkkainen H, Aaltonen K, Milne RL, Heikkila P, Aittomaki K, et al. The breast cancer susceptibility mutation PALB2 1592delT is associated with an aggressive tumor phenotype. Clin Cancer Res. 2009;15(9):3214-22. doi:10.1158/ 1078-0432.CCR-08-3128.

21. Keogh LA, Southey MC, Maskiell J, Young MA, Gaff CL, Kirk J, et al. Uptake of offer to receive genetic information about BRCA1 and BRCA2 mutations in an Australian population-based study. Cancer Epidemiol Biomarkers Prev. 2004;13(12):2258-63.

22. Peterlongo P, Catucci I, Colombo M, Caleca L, Mucaki E, Bogliolo M, et al. FANCM c.5791C > T nonsense mutation (rs144567652) induces exon skipping, affects DNA repair activity and is a familial breast cancer risk factor Hum Mol Genet. 2015:24(18):5345-55. doi:10.1093/hmg/ddv251.

23. Cybulski C, Carrot-Zhang J, Kluzniak W, Rivera B, Kashyap A, Wokolorczyk D, et al. Germline RECQL mutations are associated with breast cancer susceptibility. Nat Genet. 2015;47(6):643-6. doi:10.1038/ng.3284.

24. Southey MC, Park DJ, Nguyen-Dumont T, Campbell I, Thompson E, Traine $\mathrm{AH}$, et al. COMPLEXO: identifying the missing heritability of breast cancer via next generation collaboration. Breast Cancer Res. 2013;15(3):402. doi:10. $1186 /$ bcr3434

25. Vietri MT, Caliendo G, Casamassimi A, Cioffi M, De Paola ML, Napoli C, et al. A novel PALB2 truncating mutation in an Italian family with male breast cancer. Oncol Rep. 2015;33(3):1243-7. doi:10.3892/or.2014.3685.

26. Peterlongo P, Catucci I, Pasquini G, Verderio P, Peissel B, Barile M, et al. PALB2 germline mutations in familial breast cancer cases with personal and family history of pancreatic cancer. Breast Cancer Res Treat. 2011;126(3):825-8. doi:10. 1007/s10549-010-1305-1.

27. Tischkowitz MD, Sabbaghian N, Hamel N, Borgida A, Rosner C, Taherian N, et al. Analysis of the gene coding for the BRCA2-interacting protein PALB2 in familial and sporadic pancreatic cancer. Gastroenterology. 2009:137(3): 1183-6. doi:10.1053/j.gastro.2009.06.055.

28. Hofstatter EW, Domchek SM, Miron A, Garber J, Wang M, Componeschi K, et al. PALB2 mutations in familial breast and pancreatic cancer. Fam Cancer. 2011:10(2):225-31. doi:10.1007/s10689-011-9426-1.

29. Slater EP, Langer P, Niemczyk E, Strauch K, Butler J, Habbe N, et al. PALB2 mutations in European familial pancreatic cancer families. Clin Genet. 2010; 78(5):490-4. doi:10.1111/j.1399-0004.2010.01425.x.

30. Ghiorzo P, Pensotti V, Fornarini G, Sciallero S, Battistuzzi L, Belli F, et al. Contribution of germline mutations in the BRCA and PALB2 genes to pancreatic cancer in Italy. Fam Cancer. 2012;11(1):41-7. doi:10.1007/ s10689-011-9483-5.

31. Harinck F, Kluijt I, van Mil SE, Waisfisz Q, van Os TA, Aalfs CM, et al. Routine testing for PALB2 mutations in familial pancreatic cancer families and breast cancer families with pancreatic cancer is not indicated. Eur J Hum Genet. 2012:20(5):577-9. doi:10.1038/ejhg.2011.226.

32. Salo-Mullen EE, O'Reilly EM, Kelsen DP, Ashraf AM, Lowery MA, Yu KH, et al. Identification of germline genetic mutations in patients with pancreatic cancer. Cancer. 2015;121(24):4382-8. doi:10.1002/cncr.29664.

33. Waddell N, Pajic M, Patch AM, Chang DK, Kassahn KS, Bailey P, et al. Whole genomes redefine the mutational landscape of pancreatic cancer. Nature. 2015:518(7540):495-501. doi:10.1038/nature14169.

34. Ramus SJ, Song H, Dicks E, Tyrer JP, Rosenthal AN, Intermaggio MP, et al. Germline Mutations in the BRIP1, BARD1, PALB2, and NBN Genes in Women With Ovarian Cancer. J Natl Cancer Inst. 2015;107:11. doi:10.1093/jnci/djv214. 
35. Norquist BM, Harrell MI, Brady MF, Walsh T, Lee MK, Gulsuner S et al. Inherited Mutations in Women With Ovarian Carcinoma. JAMA Oncol. 2015: 1-9. doi:10.1001/jamaoncol.2015.5495.

36. Tischkowitz M, Easton DF, Ball J, Hodgson SV, Mathew CG. Cancer incidence in relatives of British Fanconi Anaemia patients. BMC Cancer. 2008;8:257. doi: 10.1186/1471-2407-8-257.

37. Tischkowitz M, Sabbaghian N, Ray AM, Lange EM, Foulkes WD, Cooney KA. Analysis of the gene coding for the BRCA2-interacting protein PALB2 in hereditary prostate cancer. Prostate. 2008;68(6):675-8. doi:10.1002/pros.20729.

38. Mantere T, Haanpaa M, Hanenberg H, Schleutker J, Kallioniemi A, Kahkonen M, et al. Finnish Fanconi anemia mutations and hereditary predisposition to breast and prostate cancer. Clin Genet. 2015;88(1):68-73. doi:10.1111/cge.12447.

39. Pakkanen $\mathrm{S}$, Wahlfors $\mathrm{T}$, Siltanen $\mathrm{S}$, Patrikainen M, Matikainen MP, Tammela $\mathrm{TL}$, et al. PALB2 variants in hereditary and unselected Finnish prostate cancer cases. J Negat Results Biomed. 2009:8:12. doi:10.1186/1477-5751-8-12.

40. Cybulski C, Kluzniak W, Huzarski T, Wokolorczyk D, Kashyap A, Jakubowska A, et al. Clinical outcomes in women with breast cancer and a PALB2 mutation: a prospective cohort analysis. Lancet Oncol. 2015;16(6):638-44. doi:10.1016/ S1470-2045(15)70142-7.

41. Teo ZL, Provenzano E, Dite GS, Park DJ, Apicella C, Sawyer SD, et al. Tumour morphology predicts PALB2 germline mutation status. Br J Cancer. 2013; 109(1):154-63. doi:10.1038/bjc.2013.295

42. PROMPT. https://promptinfo.squarespace.com/about-us/.

43. Memorial Sloan Kettering Cancer Center. New Academic-Industry Partnership creates online registry for patients tested for inherited cancer risk. 2014. https:// www.mskcc.org/press-releases/new-academic-industry-partnership-createsonline-registry-patients-tested-inherited-risk

44. Tavtigian SV, Chenevix-Trench G. Growing recognition of the role for rare missense substitutions in breast cancer susceptibility. Biomark Med. 2014; 8(4):589-603. doi:10.2217/bmm.13.143.

45. Tischkowitz M, Capanu M, Sabbaghian N, Li L, Liang X, Vallee MP, et al. Rare germline mutations in PALB2 and breast cancer risk: a population-based study. Hum Mutat. 2012;33(4):674-80. doi:10.1002/humu.22022.

46. Scott $C L$, Jenkins MA, Southey MC, Davis TA, Leary JA, Easton DF, et al Average age-specific cumulative risk of breast cancer according to type and site of germline mutations in BRCA1 and BRCA2 estimated from multiplecase breast cancer families attending Australian family cancer clinics. Hum Genet. 2003;112(5-6):542-51. doi:10.1007/s00439-003-0908-6.

47. Tavtigian SV, Oefner PJ, Babikyan D, Hartmann A, Healey S, Le Calvez-Kelm $F$, et al. Rare, evolutionarily unlikely missense substitutions in ATM confer increased risk of breast cancer. Am J Hum Genet. 2009;85(4):427-46.

48. Le Calvez-Kelm F, Lesueur F, Damiola F, Vallee M, Voegele C, Babikyan D, et al. Rare, evolutionarily unlikely missense substitutions in CHEK2 contribute to breast cancer susceptibility: results from a breast cancer family registry case-control mutation-screening study. Breast Cancer Res. 2011;13(1):R6. doi: 10.1186/bcr2810.

49. Lovelock PK, Spurdle AB, Mok MT, Farrugia DJ, Lakhani SR, Healey S, et al. Identification of BRCA1 missense substitutions that confer partial functional activity: potential moderate risk variants? Breast Cancer Res. 2007:9(6):R82. doi:10.1186/bcr1826

50. Spurdle AB, Whiley PJ, Thompson B, Feng B, Healey S, Brown MA, et al. BRCA1 R1699Q variant displaying ambiguous functional abrogation confers intermediate breast and ovarian cancer risk. J Med Genet. 2012;49(8):525-32. doi:10.1136/jmedgenet-2012-101037.

51. Michailidou K, Hall P, Gonzalez-Neira A, Ghoussaini M, Dennis J, Milne RL, et al. Large-scale genotyping identifies 41 new loci associated with breast cancer risk. Nat Genet. 2013;45(4):353-61. doi:10.1038/ng.2563. 61e1-2.

52. Meeks HD, Song H, Michailidou K, Bolla MK, Dennis J, Wang Q et al. BRCA2 Polymorphic Stop Codon K3326X and the Risk of Breast, Prostate, and Ovarian Cancers. J Natl Cancer Inst. 2016;108(2). doi:10.1093/jnci/djv315.

53. ENIGMA Consortium. http://enigmaconsortium.org.

54. Spurdle AB, Healey S, Devereau A, Hogervorst FB, Monteiro AN, Nathanson $\mathrm{KL}$, et al. ENIGMA-evidence-based network for the interpretation of germline mutant alleles: an international initiative to evaluate risk and clinical significance associated with sequence variation in BRCA1 and BRCA2 genes. Hum Mutat. 2012;33(1):2-7. doi:10.1002/humu.21628.

55. Nguyen-Dumont T, Stewart J, Winship I, Southey MC. Rare genetic variants: making the connection with breast cancer susceptibility. AIMS Genet. 2015; 2(4):281-92. doi:10.3934/genet.2015.4.281.

56. Park JY, Singh TR, Nassar N, Zhang F, Freund $M$, Hanenberg $H$, et al. Breast cancer-associated missense mutants of the PALB2 WD40 domain, which directly binds RAD51C, RAD51 and BRCA2, disrupt DNA repair. Oncogene. 2014:33(40):4803-12. doi:10.1038/onc.2013.421.

57. Guidugli L, Pankratz VS, Singh N, Thompson J, Erding CA, Engel C, et al. A classification model for BRCA2 DNA binding domain missense variants based on homology-directed repair activity. Cancer Res. 2013;73(1):265-75 doi:10.1158/0008-5472.CAN-12-2081.

58. Quiles F, Fernandez-Rodriguez J, Mosca R, Feliubadalo L, Tornero E, Brunet J, et al. Functional and structural analysis of C-terminal BRCA1 missense variants. PLoS ONE. 2013;8(4), e61302. doi:10.1371/journal.pone.0061302.

59. Jhuraney A, Velkova A, Johnson RC, Kessing B, Carvalho RS, Whiley P, et al. BRCA1 Circos: a visualisation resource for functional analysis of missense variants. J Med Genet. 2015;52(4):224-30. doi:10.1136/jmedgenet-2014-102766.

60. Millot GA, Carvalho MA, Caputo SM, Vreeswijk MP, Brown MA, Webb M, et al. A guide for functional analysis of BRCA1 variants of uncertain significance. Hum Mutat. 2012;33(11):1526-37. doi:10.1002/humu.22150.

\section{Submit your next manuscript to BioMed Central and we will help you at every step:}

- We accept pre-submission inquiries

- Our selector tool helps you to find the most relevant journal

- We provide round the clock customer support

- Convenient online submission

- Thorough peer review

- Inclusion in PubMed and all major indexing services

- Maximum visibility for your research

Submit your manuscript at www.biomedcentral.com/submit
) Biomed Central 